\title{
Silagem de grãos úmidos de milho de textura dura ou macia em dietas com polpa cítrica para vacas em lactação
}

\author{
[High moisture silage of hard or soft corn grain in citrus pulp diets for lactating cows] \\ F.M.J. Costa ${ }^{1}$, G.S. Dias Júnior ${ }^{1}$, O.F. Zacaroni ${ }^{1}$, J.F. Santos ${ }^{1}$, \\ R.A.N. Pereira ${ }^{2}$, M.N. Pereira ${ }^{1 *}$ \\ ${ }^{1}$ Universidade Federal de Lavras - UFLA - Lavras, MG \\ ${ }^{2}$ Empresa de Pesquisa Agropecuária de Minas Gerais - Epamig - Lavras, MG
}

\begin{abstract}
RESUMO
Avaliou-se o desempenho de vacas leiteiras que consumiram polpa cítrica e dois teores dietéticos de silagem de grão úmido de milho. Os tratamentos foram: milho de textura dura ou milho de textura macia ensilado na linha negra, em fatorial com $9 \%$ ou $18 \%$ de milho na dieta. O teor de polpa cítrica na dieta foi de $16,2 \%$ ou $25,6 \%$, com alto e baixo milho, respectivamente. Doze vacas receberam os tratamentos em quadrados latinos $4 \times 4$. A produção diária de leite foi $27,9 \mathrm{~kg}$ no milho duro e 28,8 no macio $(P=0,19)$. Alto milho diminuiu o teor de gordura do leite de 3,38 para $3,26 \%(P=0,04)$ e aumentou o teor de proteína de 2,99 para 3,03\% ( $P=0,05)$ e a eficiência alimentar de 1,50 para $1,57 \mathrm{~kg}$ de leite $/ \mathrm{kg}$ de consumo $(P=0,03)$. Aumento no teor de milho induziu maior queda no $\mathrm{pH}$ ruminal na dieta com milho macio do que na dieta com milho duro $(P=0,05$ para a interação textura versus teor de milho). $\mathrm{O}$ milho macio aumentou o consumo diário de matéria orgânica digestível de 11,7 para $12,3 \mathrm{~kg}(P=0,05)$. Os parâmetros digestivos sugerem que a ensilagem não eliminou totalmente o efeito da textura do endosperma sobre a digestibilidade do milho.
\end{abstract}

Palavras-chave: vaca, endosperma do milho, milho dentado, milho farináceo, milho flint, vitreosidade do milho

\begin{abstract}
Lactating cow performance on diets containing citrus pulp and two levels of high moisture corn silage was evaluated. Treatments were: hard texture corn or soft texture corn ensiled at the black layer, with a $9 \%$ or $18 \%$ factorial corn in the diet. Dietary citrus pulp content was $16.2 \%$ or $25.6 \%$, for high and low corn, respectively. Twelve cows received the treatments in $4 x 4$ Latin Squares. Daily milk yield was $27.9 \mathrm{~kg}$ for hard corn and 28.8 for soft $(P=0.19)$. High corn decreased milk fat content from 3.38 to $3.26 \%$ $(P=0.04)$, and increased protein content from 2.99 to $3.03 \%(P=0.05)$ and feed efficiency from 1.50 to $1.57 \mathrm{~kg}$ of milk/kg of intake $(P=0.03)$. The increase of corn content generated a greater decrease in ruminal $\mathrm{pH}$ in the soft corn diet than in the hard corn diet $(P=0.05$ for the interaction of texture versus corn content). Soft corn increased the daily intake of digestible organic matter from 11.7 to $12.3 \mathrm{~kg}$ $(P=0.05)$. Digestive parameters suggest that ensilaging did not totally eliminate the endosperm texture effect on corn digestibility.
\end{abstract}

Keywords: cow, corn endosperm, corn vitreousness, dent corn, flint corn, floury corn

\section{INTRODUÇÃO}

Os híbridos de milho cultivados no Brasil são majoritariamente de endosperma duro, ou vítreo, rico em matriz proteica e, portanto, de baixa digestibilidade do amido (Corrêa et al., 2002; McAllister et al., 1993). Em dietas baseadas em

Recebido em 23 de julho de 2013

Aceito em 29 de novembro de 2013

* Autor para correspondência (corresponding author)

E-mail: mpereira@dzo.ufla.br milho duro, a perda em conteúdo energético quando o milho é substituído por polpa cítrica parece ser de baixa magnitude (Pereira et al., 2007). A inclusão de polpa de citros em substituição parcial ao milho na dieta de vacas leiteiras se justifica por ser o Brasil o maior produtor mundial desse subproduto da indústria de sucos, rico em pectina, sacarose e fibra de alta 
digestibilidade (Miron et al., 2001), podendo ser uma opção atrativa financeiramente (Salvador et al., 2008b).

Entretanto, híbridos de milho com alta vitreosidade do endosperma podem reduzir a degradabilidade do amido e o fluxo ruminal de proteína microbiana, especialmente em dietas com alta inclusão de polpa cítrica. Salvador et al. (2008b) verificaram que a substituição total de milho por polpa cítrica reduziu a secreção diária de leite e proteína, comparativamente a uma dieta contendo $10 \%$ de milho maduro finamente moído. O potencial de síntese de proteína microbiana no rúmen em dietas à base de pectina parece ser menor que em dietas à base de amido (Marounek e Dusková, 1999; Hall e Herejk, 2001). Nas dietas em que polpa cítrica substitui o milho, é pertinente quantificar a resposta animal à variação na inclusão dietética de milho.

A ensilagem de milho grão com teor de umidade acima de $30 \%$ pode aumentar a digestibilidade do amido no rúmen e no trato digestivo total (Oba e Allen, 2003; Ferraretto et al., 2013). Durante a ensilagem ocorre proteólise por enzimas microbianas da matriz proteica no endosperma de cereais, uma estratégia plausível para aumentar a digestibilidade de grãos de milho com textura dura (Baron et al., 1986; Hoffman et al., 2011). A ensilagem do milho duro pode contrapor o efeito negativo da textura sobre a digestibilidade do grão (Philippeau e Michalet-Doureau, 1998; Andrade Filho et al., 2010).

O objetivo deste experimento foi avaliar o desempenho de vacas leiteiras que consumiram polpa cítrica e dois teores dietéticos de grãos de milho de textura dura ou textura macia do endosperma, ensilados no estágio de maturação de linha negra.

\section{MATERIAL E MÉTODOS}

Doze vacas da raça Holandesa, oito multíparas e quatro primíparas, com $111 \pm 50$ dias em lactação no início do período experimental, foram individualmente alimentadas em confinamento total do tipo tie stall com camas de areia. As multíparas foram blocadas em dois grupos de quatro animais com base na produção de leite e aleatoriamente alocadas a uma das sequências de quatro tratamentos em dois quadrados latinos $4 \times 4$, com períodos de 21 dias. Um terceiro quadrado latino foi constituído apenas por primíparas. Os três quadrados foram conduzidos simultaneamente e a sequência de aplicação dos tratamentos objetivou balanceamento para efeito residual.

Um arranjo fatorial $2 \times 2$ de dois fatores, textura do endosperma do milho e teor dietético de milho, definiu os quatro tratamentos: silagem de grão macio e milho alto, silagem de grão duro e milho alto, silagem de grão macio e milho baixo, e silagem de grão duro e milho baixo (Tab. 1). Os grãos com textura dura do endosperma (Novartis Tork, Sementes Syngenta, Uberlândia, MG) e de textura macia (Agroceres AG 4051, Sementes Agroceres, Uberlândia, MG) foram colhidos no estágio de maturação de linha negra (66,6\% de MS para o híbrido duro e $68,4 \%$ para o dentado) e ensilados após moagem fina e com uso de inoculante (Biomax $5^{\circledR}$, Chr. Hansen, Valinhos, SP) em silos tipo trincheira, dimensionados para descarregamento de toda superfície externa em fatias diárias nunca inferiores a $20 \mathrm{~cm}$ de profundidade. A vitreosidade dos grãos, determinada segundo Dombrink-Kurtzman e Bietz (1993), foi 68,2\% do endosperma para o grão duro e $48,5 \%$ para o macio, e a idade das plantas à colheita foi de 124 e de 131 dias, respectivamente. A distribuição de tamanho de partículas das silagens foi determinada por agitação por 5 minutos de amostras desidratadas em estufa ventilada a $55^{\circ} \mathrm{C}$ por 72 horas (Tab. 2).

Os ingredientes dietéticos foram pesados e fornecidos duas vezes ao dia na forma de dieta completa, propiciando pelo menos $15 \%$ do oferecido como sobra diária. A proporção de ingredientes na matéria seca dietética foi mantida constante por monitoramento semanal da porcentagem de matéria seca da silagem de milho e das silagens de grão úmido por desidratação em aparelho do tipo Koster (Koster Crop Tester, Strongsville, EUA). Nos dias 16 a 20 de cada período, as sobras alimentares de cada vaca foram amostradas e congeladas. Amostras compostas foram formadas por vaca e por período por união de quantidades idênticas de matéria natural das sobras diárias. Nos dias 15 a 19 também foram coletadas amostras diárias da silagem de milho, das silagens de grão úmido, do feno de Tifton e dos outros alimentos concentrados; uma amostra composta foi formada para cada alimento por período. 
Silagem de grãos...

Tabela 1. Composição das dietas (\% da Matéria Seca) nos tratamentos silagem de grão macio e milho alto (M/A), silagem de grão duro e milho alto (D/A), silagem de grão macio e milho baixo (M/B), e silagem de grão duro e milho baixo (D/B)

\begin{tabular}{|c|c|c|c|c|}
\hline & $\mathrm{D} / \mathrm{A}$ & $\mathrm{D} / \mathrm{B}$ & $\mathrm{M} / \mathrm{A}$ & $\mathrm{M} / \mathrm{B}$ \\
\hline Silagem de milho & 34,2 & 33,9 & 33,8 & 33,7 \\
\hline Feno de Tifton & 15,7 & 15,6 & 15,5 & 15,6 \\
\hline Silagem de milho úmido duro & 17,2 & 8,5 & & \\
\hline Silagem de milho úmido macio & & & 18,3 & 9,0 \\
\hline Polpa cítrica & 16,4 & 25,7 & 16,1 & 25,6 \\
\hline Farelo de soja & 13,7 & 13,6 & 13,5 & 13,4 \\
\hline Ureia & 0,8 & 0,8 & 0,8 & 0,8 \\
\hline Bicarbonato de sódio & 0,8 & 0,8 & 0,8 & 0,8 \\
\hline Mineral & 0,3 & 0,3 & 0,3 & 0,3 \\
\hline Calcário calcítico & 0,4 & 0,4 & 0,4 & 0,4 \\
\hline Sal & 0,3 & 0,3 & 0,3 & 0,3 \\
\hline Proteína bruta & 15,4 & 15,0 & 15,3 & 15,3 \\
\hline FDN de Tifton & 11,5 & 10,3 & 11,3 & 10,9 \\
\hline FDN de silagem de milho & 16,2 & 15,7 & 15,7 & 15,2 \\
\hline FDN total & 32,9 & 34,7 & 32,8 & 34,7 \\
\hline Cinzas & 6,0 & 6,3 & 6,0 & 6,4 \\
\hline Extrato etéreo & 2,9 & 2,7 & 2,8 & 2,6 \\
\hline Carboidratos não fibrosos & 42,8 & 41,2 & 43,2 & 41,0 \\
\hline
\end{tabular}

Mineral: 18,5\% de Ca; $15 \%$ de P; 3,0\% de Mg; 3,0\% de S; 240 ppm de Co; 3.000 ppm de Cu; 8.000ppm de Mn; 12.000 ppm de Zn; 90 ppm de Se; 180 ppm de I. FDN: Fibra em detergente neutro. Carboidratos não fibrosos: 100 (Proteína bruta + FDN + Cinzas + Extrato etéreo).

Tabela 2. Partículas das silagens de grão úmido de milho duro (Duro) e macio (Macio) retidas em peneiras

\begin{tabular}{|c|c|c|}
\hline \multirow{2}{*}{$\begin{array}{l}\text { Diâmetro do } \\
\text { orifício }\end{array}$} & Duro & Macio \\
\hline & \multicolumn{2}{|c|}{$\%$ da matéria seca } \\
\hline$>2 \mathrm{~mm}$ & 62,5 & 66,3 \\
\hline$>1 \mathrm{~mm} \mathrm{e}<2 \mathrm{~mm}$ & 22,5 & 16,9 \\
\hline$>0,5 \mathrm{~mm} \mathrm{e}<1 \mathrm{~mm}$ & 10,1 & 7,9 \\
\hline$>0,25 \mathrm{~mm} \mathrm{e}<0,5 \mathrm{~mm}$ & 3,3 & 6,6 \\
\hline$>0,105 \mathrm{~mm} \mathrm{e}<0,25 \mathrm{~mm}$ & 1,5 & 2,2 \\
\hline$<0,105 \mathrm{~mm}$ & 0,1 & 0,1 \\
\hline
\end{tabular}

Os compostos de sobras e alimentos foram desidratados em estufa ventilada por 72 horas a $55^{\circ} \mathrm{C}$ e moídas em moinho tipo Thomas-Wiley com peneira de $1 \mathrm{~mm}$. Uma subamostra foi levada à estufa de $105^{\circ} \mathrm{C}$ por 24 horas, para determinação do teor de matéria seca. A proteína bruta foi determinada por aparelho de destilação a vapor Microkjeldahll (Association..., 1975). Determinou-se o conteúdo de cinzas por incineração a $550^{\circ} \mathrm{C}$ por 8 horas. A FDN livre de cinzas foi determinada segundo Van Soest et al. (1991), utilizando sulfito de sódio e amilase estável ao calor. O extrato etéreo foi determinado segundo o Association of Official Agricultural Chemists - AOAC (Association..., 1980).

O consumo diário de matéria seca (CMS) entre os dias 15 a 20 de cada período foi calculado. As vacas foram ordenhadas duas vezes ao dia, às $5 \mathrm{~h}$ e às 16 h. Nos dias 17,18 e 19 de cada período, o leite foi pesado e, em uma amostra de cada ordenha, foram determinados os teores de sólidos e nitrogênio ureico (Clínica do Leite, Piracicaba, $\mathrm{SP})$. A secreção diária de energia no leite foi calculada pela equação ((National..., 2001): kg de leite $\mathrm{x}[(0,0929 \times \%$ gordura $)+(0,0547 \times \%$ de proteína $)+(0,0395 \times \%$ de lactose $)]$. Definiuse a eficiência alimentar pela relação entre a produção diária de leite e o CMS. A eficiência na utilização energética foi estimada pelas relações entre a secreção diária de energia e o CMS, e entre a secreção diária de energia e o consumo de matéria orgânica digestível (CMOD). Nos dias 17 a 19 de cada período, o peso vivo, e, no dia 21 , a condição corporal, foram mensurados para descrever as unidades experimentais. A condição corporal, definida em escala de 1 a 5 (Wildman et al., 1982), foi avaliada visualmente por dois avaliadores independentes. 
A digestibilidade aparente no trato digestivo total da matéria seca, da matéria orgânica, da fibra em detergente neutro e da matéria orgânica não FDN foi determinada por coleta total de fezes realizada por 8 horas ininterruptas nos dias 17 a 19. A coleta de fezes em cada dia foi iniciada com 8 horas de atraso em relação ao dia anterior, visando obter uma amostragem representativa de 24 horas do dia sem causar distúrbio no consumo de alimentos e na produção de leite dos animais. As fezes foram continuamente congeladas durante a coleta e uma amostra composta foi formada para cada vaca em cada período. Os compostos de fezes foram desidratados e os conteúdos de FDN e cinzas foram determinados como anteriormente descrito para os alimentos. Calculou-se o CMOD. $\mathrm{O} \quad \mathrm{pH}$ fecal foi determinado no início e no final de cada período de 8 horas de coleta total de fezes, totalizando seis pontos ao longo de 24 horas, por diluição de $50 \mathrm{~g}$ de fezes em $50 \mathrm{~mL}$ de água destilada e mensuração imediata do $\mathrm{pH}$ da solução. $\mathrm{O}$ pH fecal de cada vaca foi a média das seis amostras fecais.

A concentração de derivados purínicos na urina foi mensurada para estimar a produção relativa de proteína microbiana no rúmen. Uma amostra de urina foi coletada no início e no final de cada um dos três períodos de oito horas de coleta de fezes, perfazendo seis amostras por vaca por período experimental. Ao volume de urina coletado em cada amostragem foram imediatamente adicionados $10 \%$ de uma solução de ácido sulfúrico a $10 \%$ e a amostra foi armazenada a $4^{\circ} \mathrm{C}$. Formou-se uma amostra composta para cada vaca no final de cada período. As amostras compostas foram diluídas com água destilada na proporção 1:3 (urina: água) e congeladas a $-20^{\circ} \mathrm{C}$ até a realização das análises de alantoína, ácido úrico e creatinina. Para a análise de alantoína, o procedimento adotado foi semelhante ao sugerido por Chen e Gomes (1992). Para as análises de ácido úrico e creatinina, foram utilizados kits de análise laboratorial (Labtest Diagnóstica S.A., Lagoa Santa, MG, Cat. 73-4/30 para ácido úrico e Cat. 35-100 para creatinina).

No dia 21 foram obtidas amostras de fluido ruminal para determinação do $\mathrm{pH}$. A amostragem ocorreu 13,2 $\pm 0,1$ horas (média \pm desvio padrão) após a alimentação da manhã. A retirada do fluido ruminal foi realizada por aspiração percutânea do saco ventral do rúmen (Ruminocentese) (Garrett et al., 1999) e seguindo as recomendações éticas no uso de animais na experimentação científica. Os animais foram amostrados aleatoriamente dentro de quadrado.

As análises estatísticas foram realizadas usando o procedimento GLM do SAS (Statistical..., 19992000) com o seguinte modelo: $Y_{i j k l m}=\mu+Q_{i}+$ $\mathrm{V}_{\mathrm{j}(\mathrm{i})}+\mathrm{P}_{\mathrm{k}}+\mathrm{E}_{\mathrm{l}}+\mathrm{M}_{\mathrm{m}}+\mathrm{EM}_{\mathrm{lm}}+\varepsilon_{\mathrm{ijklm}}$, em que: $\mu=$ média geral; $\mathrm{Q}_{\mathrm{i}}=$ efeito de quadrado $(\mathrm{i}=1$ a 3 ); $\mathrm{V}_{\mathrm{j}(\mathrm{i})}=$ efeito de vaca dentro de quadrado $(\mathrm{j}=1 \mathrm{a}$ 12); $\mathrm{P}_{\mathrm{k}}=$ efeito de período $(\mathrm{k}=1 \mathrm{a} 4) ; \mathrm{E}_{1}=$ efeito de tipo de endosperma do milho $(1=$ duro, macio); $\mathrm{M}_{\mathrm{m}}=$ efeito de teor de milho ensilado ( $\mathrm{m}$ = baixo, alto) $\mathrm{EM}_{\mathrm{lm}}=$ Interação entre tipo de endosperma versus teor de milho ensilado; $\varepsilon_{\mathrm{ijklm}}=$ erro residual.

\section{RESULTADOS E DISCUSSÃO}

Não foi detectado efeito do teor de milho na dieta sobre a produção diária de leite (Tab. 3). Apesar de a substituição de milho por polpa de citros ser capaz de atuar negativamente sobre a produção de leite (Broderick et al., 2002; Salvador et al., 2008b), os resultados aqui obtidos evidenciram que, nesse tipo de formulação dietética (Tab. 1), a polpa cítrica resultou em produção diária similar à do milho ensilado. Entretanto, as dietas com maior teor de milho melhoraram a eficiência alimentar definida pela relação entre o leite produzido e o CMS (Tab. 3).

A alta inclusão de milho, mesmo não afetando o volume diário de leite, aumentou o teor de proteína de 2,99 para $3,03 \%$ e reduziu o de gordura de 3,38 para $3,26 \%$. O aumento no teor de gordura foi percentualmente três vezes superior à queda induzida no teor de proteína. Em sistemas de pagamento do leite por qualidade, em que a remuneração por proteína é alta comparativamente à remuneração por gordura, o maior custo das dietas com maior inclusão de milho pode ser compensado pelo maior valor da produção vendida. Entretanto, dietas com alta inclusão de polpa cítrica podem ser interessantes quando existe pagamento do leite com ênfase em teor de gordura.

A substituição de milho de textura dura por milho de textura macia não teve efeito sobre o 
teor de sólidos do leite. Entretanto, a silagem de grão dentado induziu aumento numérico na produção diária de leite de 27,9 para $28,8 \mathrm{~kg}$ e, na de proteína, de 0,837 para $0,865 \mathrm{~kg}$. Apesar de o experimento não ter sido capaz de suportar estatisticamente essas diferenças no desempenho animal, outros indicadores sugerem que o milho macio ensilado foi mais digerido que o duro. $\mathrm{O}$ CMOD, um indicador da ingestão diária de energia por vaca, foi maior com grão macio, e houve tendência de maior digestibilidade aparente da matéria orgânica não fibrosa nesse tratamento (Tab. 4). Aumento na inclusão dietética de milho ensilado também induziu maior queda no $\mathrm{pH}$ ruminal na dieta com milho macio do que na com duro (Tab. 4). A ensilagem do grão duro, uma maneira de induzir degradação da matriz proteica circundando os grânulos de amido do endosperma (Baron et al., 1986; McAllistter et al., 1993), parece não ter resultado em digestibilidade desse grão similar à do macio.

Tabela 3. Desempenho de vacas leiteiras nos tratamentos silagem de grão macio e milho alto (M/A), silagem de grão duro e milho alto (D/A), silagem de grão macio e milho baixo (M/B), e silagem de grão duro e milho baixo (D/B)

\begin{tabular}{|c|c|c|c|c|c|c|c|c|}
\hline & $\mathrm{D} / \mathrm{A}$ & $\mathrm{D} / \mathrm{B}$ & $\mathrm{M} / \mathrm{A}$ & $\mathrm{M} / \mathrm{B}$ & EPM & Tex & $\mathrm{Mi}$ & Int \\
\hline \multicolumn{9}{|c|}{$\mathrm{kg} \mathrm{d}^{-1}$} \\
\hline CMS & 17,6 & 18,4 & 18,5 & 18,6 & 0,29 & 0,08 & 0,16 & 0,18 \\
\hline CMOD & 11,5 & 11,9 & 12,5 & 12,1 & 0,30 & 0,05 & 0,90 & 0,16 \\
\hline Leite & 27,5 & 28,3 & 29,3 & 28,3 & 0,68 & 0,19 & 0,91 & 0,18 \\
\hline Gordura & 0,901 & 0,944 & 0,934 & 0,957 & 0,020 & 0,26 & 0,13 & 0,63 \\
\hline Proteína & 0,834 & 0,840 & $\begin{array}{c}0,887 \\
\%\end{array}$ & 0,843 & 0,020 & 0,17 & 0,37 & 0,23 \\
\hline Gordura & 3,29 & 3,34 & 3,22 & 3,42 & 0,058 & 0,99 & 0,04 & 0,19 \\
\hline Proteína & 3,03 & 3,00 & $\begin{array}{r}3,04 \\
\mathrm{mg} \mathrm{dL}^{-1} \\
\end{array}$ & 3,01 & 0,019 & 0,34 & 0,05 & 0,56 \\
\hline NUL & 15,1 & 15,0 & $\begin{array}{c}15,6 \\
\text { Mcal d }^{-1} \\
\end{array}$ & 15,3 & 0,38 & 0,28 & 0,62 & 0,87 \\
\hline Energia & 18,3 & $\begin{array}{r}18,4 \\
\mathrm{k}\end{array}$ & $\begin{array}{c}18,9 \\
\text { eite } \mathrm{kg} \mathrm{C}\end{array}$ & 18,6 & 0,29 & 0,22 & 0,96 & 0,37 \\
\hline Eficiência 1 & 1,57 & 1,51 & $\begin{array}{c}1,57 \\
\text { Mcal kg-1 } \\
\end{array}$ & 1,50 & 0,028 & 0,80 & 0,03 & 0,94 \\
\hline Eficiência 2 & 1,02 & 0,98 & 1,00 & 0,99 & 0,018 & 0,79 & 0,12 & 0,53 \\
\hline \multicolumn{9}{|c|}{$\mathrm{kg}$} \\
\hline Peso vivo & 573 & 579 & 573 & 575 & 4,1 & 0,56 & 0,37 & 0,66 \\
\hline \multicolumn{9}{|c|}{1 a 5 (magra a gorda) } \\
\hline $\mathrm{CC}$ & 2,79 & 2,78 & 2,78 & 2,84 & 0,029 & 0,55 & 0,51 & 0,43 \\
\hline
\end{tabular}

$\mathrm{EPM}=$ erro padrão das médias. Valor de probabilidade $(P)$ para os efeitos de: Tex = textura do grão de milho; $\mathrm{Mi}=$ teor de silagem de milho úmido; e Int = interação Tex vs Mi. CMS = consumo de matéria seca; CMOD = consumo de matéria orgânica digestível; NUL = nitrogênio ureico no leite; Energia = energia no leite; Eficiência $1=$ Leite/CMS; Eficiência 2 = energia no leite/CMS; Eficiência 3 = energia no leite/CMOD; CC = condição corporal (escore).

A digestão pós-ruminal do amido não digerido no rúmen poderia minimizar diferenças entre dietas na digestibilidade mensurada no trato digestivo total (Knowlton et al., 1998). Não obstante, a atuação sobre a textura do grão e o teor de milho da dieta não foram capazes de induzir alteração no $\mathrm{pH}$ fecal (Tab. 4). A se julgar por essa variável, um indicador indireto de fermentação no intestino grosso, parece que eventos ruminais ou duodenais foram responsáveis pela diferença na digestibilidade da matéria orgânica não fibrosa entre as dietas, variando em perfil de carboidratos. 
Tabela 4. Digestibilidade aparente de nutrientes no trato digestivo total, $\mathrm{pH}$ ruminal e fecal, e derivados purínicos na urina nos tratamentos silagem de grão macio e milho alto (M/A), silagem de grão duro e milho alto (D/A), silagem de grão macio e milho baixo (M/B), e silagem de grão duro e milho baixo (D/B)

\begin{tabular}{lccccccccc}
\hline & D/A & D/B & M/A & M/B & EPM & Tex & Mi & Int \\
\hline & \multicolumn{7}{c}{ \% do consumido } \\
DMS & 67,9 & 67,8 & 69,5 & 67,9 & 1,22 & 0,50 & 0,49 & 0,55 \\
DMO & 70,0 & 69,8 & 72,1 & 70,3 & 1,15 & 0,25 & 0,38 & 0,49 \\
DFDN & 46,1 & 49,8 & 48,9 & 49,1 & 2,18 & 0,62 & 0,38 & 0,42 \\
DMOnFDN & 83,1 & 81,7 & 84,4 & 82,7 & 0,66 & 0,10 & 0,03 & 0,80 \\
& & & & & & & & \\
pH ruminal & 6,04 & 6,07 & 5,86 & 6,22 & 0,09 & 0,85 & 0,04 & 0,05 \\
pH fecal & 6,77 & 6,75 & 6,77 & 6,77 & 0,02 & 0,66 & 0,60 & 0,41 \\
& & & & & & & & \\
Ala/Crea & 3,32 & 4,48 & 3,93 & 3,90 & 0,50 & 0,98 & 0,27 & 0,24 \\
(Au+Ala)/Crea & 3,52 & 4,77 & 4,22 & 4,27 & 0,53 & 0,85 & 0,23 & 0,26 \\
\hline EPM=
\end{tabular}

EPM = erro padrão das médias. Valor de probabilidade $(P)$ para os efeitos de Tex = textura do grão de milho; $\mathrm{Mi}=$ teor de silagem de milho úmido; Int = interação Tex vs Mi. DMS = digestibilidade da matéria seca; DMO = digestibilidade da matéria orgânica; DFDN = digestibilidade da fibra em detergente neutro; DMOnFDN = digestibilidade da matéria orgânica não FDN; $\mathrm{Au}=$ ácido úrico; $\mathrm{Ala}=$ alantoína; Crea = creatinina na urina.

O aumento no teor dietético de polpa cítrica aparentemente reduziu a digestibilidade dos carboidratos não fibrosos (Tab. 4). Esse resultado sugere que o amido do milho ensilado foi de maior digestibilidade que a pectina e a sacarose da polpa cítrica. Fica o questionamento se o determinante dessa diferença foi a menor fermentabilidade da pectina e da sacarose no rúmen, comparativamente ao amido do milho, algo pouco provável (Hall et al., 1998; Miron et al. 2001), mas suportado pelo maior $\mathrm{pH}$ ruminal nas dietas com baixo milho, ou se a alta passagem de carboidratos da polpa cítrica para o duodeno limitou sua digestão (Weidner e Grant, 1994; Bhatti e Firkins, 1995), pela ausência de enzimas oriundas de sistemas anaeróbicos microbianos nessa porção do trato digestivo. Não houve efeito dos tratamentos sobre a relação entre a concentração urinária de derivados purínicos e a de creatinina, sugerindo que os tratamentos não afetaram a síntese de proteína microbiana no rúmen.

Não foi observada resposta aos tratamentos em teor de N-ureico no leite. Broderick et al. (2002) também não observaram resposta em teor de Nureico no leite quando $19 \%$ da matéria seca dietética de milho úmido ensilado foram substituídos por polpa cítrica. Teoricamente, a menor eficiência de síntese de proteína microbiana, quando pectina e sacarose substituem amido (Hall e Herejk, 2001; Sannes et al., 2002), poderia aumentar a excreção de Nureico no leite nos tratamentos com maior teor de polpa cítrica. Resposta similar em $\mathrm{N}$-ureico do leite também seria plausível à substituição de milho macio por duro, em decorrência da menor fermentabilidade do último no rúmen (Corrêa $e t$ al., 2002). Atuação sobre a textura do milho ensilado ou sobre o teor dietético de milho, nessas dietas contendo polpa cítrica, não alterou a perda de nitrogênio pelo leite.

A eficiência de utilização energética não foi alterada pelos tratamentos (Tab. 3). Assumindo que o incremento calórico, oriundo do metabolismo ruminal ou do metabolismo intermediário de ruminantes, varia pouco dentro da amplitude fisiológica na relação entre os ácidos graxos voláteis produzidos no rúmen (Orskov et al., 1979), e que a perda urinária de energia não estaria variando nesses tratamentos isonutricionais (Blaxter et al., 1966), a relação entre a secreção diária de energia no leite e o CMOD seria uma medida indireta de metano excretado por dia. Esses dados sugerem que a substituição de milho por polpa cítrica, teoricamente capaz de aumentar a proporção de acetato dentre os produtos da fermentação ruminal (Leiva et al., 2000; Broderick et al., 2002; Salvador et al., 2008a), não teve magnitude suficiente para alterar a eficiência de utilização energética nestes animais. 


\section{CONCLUSÕES}

A maior inclusão dietética de polpa cítrica, em substituição parcial ao milho ensilado, reduziu o teor de proteína, aumentou o teor de gordura e não determinou a produção diária de leite. $\mathrm{O}$ milho de textura macia do endosperma colhido e ensilado no estágio de maturação de linha negra resultou em maior consumo diário de energia por vaca. Os parâmetros digestivos sugerem que a ensilagem não eliminou totalmente o efeito da textura do endosperma sobre a digestibilidade do milho.

\section{REFERÊNCIAS}

ANDRADE FILHO, R.; REIS, R.B.; PEREIRA, M.N. et al. Degradabilidade ruminal in situ de grãos de milho maduros do tipo flint ou dentado, secos ou reconstituídos e ensilados. In: REUNIÃO ANUAL DA SOCIEDADE BRASILEIRA DE ZOOTECNIA, 47., 2010, Salvador. Anais... Bahia: [s.n.] 2010. (Resumo).

ASSOCIATION of official agricultural chemists - AOAC. Official methods of analysis. 12. ed. Washington, D.C., 1975. v.1, 1094 p.

ASSOCIATION of official agricultural chemists - AOAC. Official methods of analysis. 13.ed. Washington, D.C., 1980. v.1.

BARON, V.S.; STEVENSON, K.R.; BUCHANANSMITH, J.G. Proteolysis and fermentation of corn grain ensiled at several moisture levels and under several simulated storage methods. Can. J. Anim. Sci., v.66, p.451-461, 1986.

BHATTI, S.A.; FIRKINS, J.L. Kinetics of hydration and functional specific gravity of fibrous feed by-products. J. Anim. Sci., v.73, p.1449-1458, 1995.

BLAXTER, K.L.; CLAPPERTON, J.L.; MARTIN, A.K. The heat of combustion of urine of sheep and cattle in relation to its chemical composition and diet. Br. J. Nutr., v.20, p.449460,1966

BRODERICK, G.A.; MERTENS, D.R.; SIMONS, R. Efficacy of carbohydrate sources for milk production by cows fed diets based on alfalfa silage. J. Dairy Sci., v.85, p.1767-1776, 2002.
CHEN, X.B.; GOMES, M.J. Estimation of microbial protein supply to sheep and cattle based on urinary excretion of purine derivativesan overview of technical details. Aberdeen: International Feed Research Unit/ Rowett Research Institute, 1992. 21p. (Occasional publication).

CORRÊA, C.E.S.; SHAVER, R.D.; PEREIRA, M.N. et al. Relationship between corn vitreousness and ruminal in situ starch degradability. J. Dairy Sci., v.85, p.3008-3012, 2002.

DOMBRINK-KURTZMAN, M.A.; BIETZ, J.A. Zein composition in hard and soft endosperm of maize. Cereal Chem., v.70, p.105-108, 1993.

FERRARETTO, L.F.; CRUMP, P.M.; SHAVER, R.D. Effect of cereal grain type and corn grain harvesting and processing methods on intake, digestion, and milk production by dairy cows through a meta-analysis. J. Dairy Sci., v.96, p.533-550, 2013.

GARRETT, E.F.; PEREIRA, M.N.; NORDLUND, K.V. et al. Diagnostic methods for detection of subacute ruminal acidosis in dairy cows. J. Dairy Sci., v.82, p.1176-1178, 1999.

HALL, M.B.; HEREJK, C. Differences in yields of microbial crude protein from in vitro fermentation of carbohydrates. J. Dairy Sci., v.84, p.2486-2493, 2001.

HALL, M.B.; PELL, A.N.; CHASE, L.E. Characteristics of neutral detergent-soluble fiber fermentation by mixed ruminal microbes. Anim. Feed Sci. Technol., v.70, p.23-39, 1998.

HOFFMAN, P.C.; ESSER, N.M.; SHAVER, R.D. et al. Influence of ensiling time and inoculation on alteration of the starch-protein matrix in high-moisture corn. J. Dairy Sci., v.94, p.2465-2474, 2011.

KNOWLTON, K.F.; GLENN, B.P.; ERDMAN, R.A. Performance, ruminal fermentation, and site of starch digestion in early lactation cows fed corn grain harvested and processed differently. $J$. Dairy Sci., v.81, p.1972-1984, 1998.

LEIVA, E.; HALL, M.B.; VAN HORN, H.H. Performance of dairy cattle fed citrus pulp or corn products as sources of neutral detergentsoluble carbohydrates. J. Dairy Sci., v.83, p.2866-2875, 2000. 
MAROUNEK, M.; DUSKOVÁ, D. Metabolism of pectin in rumen bacteria Butyrivibrio fibrisolvens and Prevotella ruminicola. Letters in Appl. Microbiol., v.33, p.159-163, 1999.

McALLISTER, T.A.; PHILLIPE, R.C.; RODE, L.M. et al. Effect of protein matrix on the digestion of cereal grains by microorganisms. $J$. Anim. Sci., v.71, p.205-212, 1993.

MIRON, J.; YOSEF, E.; BEN-GHEDALIA, D. Composition and in vitro digestibility of monosaccharide constituents of selected byproducts feeds. J. Agric. Food Chem., v.49, p.2322-2326, 2001.

NATIONAL research council - NRC. Nutrient Requirements of Dairy Cattle. 7th ed. Washington: National Academy of Sciences, 2001

OBA, M.; ALLEN, M.S. Effects of corn grain conservation method on ruminal digestion kinetics for lactating dairy cows at two dietary starch concentrations. J. Dairy Sci., v.86, p.184194, 2003.

ORSKOV, E.R.; GRUBB, D.A.; SMITH, J.S. et al. Efficiency of utilization of volatile fatty acids for maintenance and energy retention in sheep. Br. J. Nutr., v.41, p.541-553, 1979.

PEREIRA, E.M.; SANTOS, F.A.P.; NUSSIO, L.G.; et al. Estimativa de energia metabolizável de rações com polpa cítrica em substituição ao milho para tourinhos em terminação. Rev. Bras. Zootec., v.36, p.216-224, 2007.

PHILIPPEAU, C.; MICHALET-DOREAU, B. Influence of genotype and ensiling of corn grain on in situ degradation of starch in the rumen. $J$. Dairy Sci., v.81, p.2178-2184, 1998.
SALVADOR, C.S.; PEREIRA, M.N.; SANTOS, J.F. et al. Resposta de vacas leiteiras à substituição total do milho por polpa cítrica e à suplementação com minerais orgânicos I: consumo e digestão. Arq. Bras. Med. Vet. Zootec., v.60, p.682-690, 2008a.

SALVADOR, C.S.; PEREIRA, M.N.; SANTOS, J.F. et al. Resposta de vacas leiteiras à substituição total do milho por polpa cítrica e à suplementação com minerais orgânicos II: desempenho e economia. Arq. Bras. Med. Vet. Zootec, v.60, p.1142-1149, 2008b.

SANNES, R.A.; MESSMAN, M.A.; VAGNONI, D.B. Form of rumen-degradable carbohydrate and nitrogen on microbial protein synthesis and protein efficiency of dairy cows. J. Dairy Sci., v.85, p.900-908, 2002.

STATISTICAL Analysis Sistem - SAS INSTITUTE. SAS/STAT User's guide. Release 8.1. SAS Institute Inc., Cary, 1999- 2000.

VAN SOEST, P.J.; ROBERTSON, J.B.; LEWIS, B.A. Methods for dietary fiber, neutral detergent fiber, and nonstarch polysaccharides in relation to animal nutrition. J. Dairy Sci., v.74, p.35833597, 1991.

WEIDNER, S.J.; GRANT, R.J. Altered ruminal mat consistency by high percentages of soybean hulls fed to lactating dairy cows. J. Dairy Sci., v.77, p.522-532, 1994

WILDMAN, E.E.; JONES, G.M.; WAGNER, P.E. et al. A dairy cow body condition scoring system and its relationship to selected production characteristics. J. Dairy Sci., v.65, p.495-501, 1982. 